\title{
Self-Assembly Kinetics of Colloidal Particles inside Monodispersed Micro-Droplet and Fabrication of Anisotropic Photonic Crystal Micro-Particles
}

\author{
Ming-Yu Zhang ${ }^{1}, \mathrm{Ke} \mathrm{Xu}^{2}$, Jian-Hong $\mathrm{Xu}{ }^{1, *}$ and Guang-Sheng Luo ${ }^{1}$ \\ 1 The State Key Lab of Chemical Engineering, Department of Chemical Engineering, Tsinghua University, \\ Beijing 100084, China; zhangmingyu68@163.com (M.-Y.Z.); gsluo@mail.tsinghua.edu.cn (G.-S.L.) \\ 2 Department of Petroleum and Geosystems Engineering, The University of Texas at Austin, \\ Austin, TX 78705, USA; thuk-xu08@utexas.edu \\ * Correspondence: xujianhong@tsinghua.edu.cn; Tel.: +86-10-62773017
}

Academic Editor: Helmut Cölfen

Received: 13 July 2016; Accepted: 18 September 2016; Published: 23 September 2016

\begin{abstract}
A new microfluidic approach to preparing anisotropic colloidal photonic crystal microparticles is developed and the self-assembly kinetics of colloidal nanoparticles is discussed. Based on the "coffee ring" effect in the self-assembly process of colloidal silica particle in strong solvent extraction environment, we successfully prepared anisotropic photonic crystal microparticles with different shapes and improved optical properties. The shapes and optical properties of photonic crystal microparticles can be controlled by adjusting the droplet size and extraction rate. We studied the self-assembly mechanism of colloidal silica particles in strong solvent extraction environment, which has potential applications in a variety of fields including optical communication technology, environmental response, photo-catalysis and chromic material.
\end{abstract}

Keywords: photonic crystal microparticles; solvent extraction; "coffee ring" effect

\section{Introduction}

Photonic crystal is known as a structural optical material consisting of materials with different dielectric constants arranging periodically in space [1,2]. It reflects light with characteristic wavelength. The characteristic wavelength is determined by the geometry and the dielectric constants, which brings important photonic crystal applications into a variety of fields including optical communication technology, environmental response, photocatalysis and chromic material [3-5].

The reflection mechanism of photonic crystal is the so-called "optical stop band". Electromagnetic waves with specific wavelength cannot pass through photonic crystal so they are reflected. The reflected electromagnetic wavelength can be calculated by Bragg's Law [6]:

$$
\lambda=2 d n_{e f f}=\left(\frac{8}{3}\right)^{\frac{1}{2}} D\left(\sum_{i} n_{i}^{2} V_{i}\right)^{\frac{1}{2}}
$$

Where $\lambda$ is the characteristic wavelength, $d$ is the characteristic spacing, $D$ is the particle size, $n_{i}$ is the reflective index of each phases, and $V_{i}$ is the volume fraction of each phase. According to Bragg's Law, we know that the reflected electromagnetic wavelength is determined by lattice size, volume fraction, etc.

The common method to fabricate photonic crystal microspheres is preparing monodispersed droplets containing colloidal silica and then drying or solidifying microdroplets into microbeads. During the dry or solidification process the colloidal silica self-assemble into photonic crystal [7]. In the 
droplet formation step, microfluidic technology has been proved to be a mature platform in recent decades. It ensures the droplets' monodispersity both in shape and in size [8-14]. In the self-assembly step, there are two major methods: non-close packing followed by immobilization of non-contacting colloidal particles' array $[15,16]$, and close packing after removing the dispersing agent of colloidal particles [17-21].

Kim et al. [22] successfully fabricated a non-close packed photonic crystal microsphere by photo-polymerizing ethoxylated trimethylolpropane triacrylate (ETPTA) resin droplets containing suspended negatively charged colloidal silica, which are generated by co-flow microfluidic devices. This approach was simple and easy for photonic crystal production, but the balls' optical property was not good enough that their application was limited. Zhao et al. [23] prepared aqueous-phase solution droplets containing cross-linked monodisperse poly(methyl methacrylate) colloidal nanoparticles, evaporated them slowly in an oil-phase solution and produced colloidal crystal beads. This is a simple way to fabricate photonic crystals. However, the evaporation process needs many hours and is too long.

From the above references, we can see that two main methods to fabricate self-assembled photonic crystal particles have been studied by many scientists. However, there are still some problems that need to be solved, such as poor optical properties and the requirement of a long preparation time.

Aiming at solving this problem, $\mathrm{Xu}$ et al. [24] prepared colloidal crystal microbeads by solvent-extraction. They produced uniform aqueous droplets containing colloidal particles by T-junction microfluidic devices, and used organic phase as extractant to remove water from the droplets in a very short period (as fast as $\sim 5 \mathrm{~min}$ ). Compared with conventional evaporation-derived solidification, solvent extraction method reduced the time required significantly and maintained considerable optical properties. Besides, they controlled the packing quality of photonic balls by changing the extraction rate and surfactant.

On the base of preparing photonic crystal balls, scientists produced anisotropic colloidal photonic crystal microparticles according to the unique structure of Janus emulsions $[10,25-27]$ so that they have much more potential applications. Yu et al. [25] developed a triphase microfluidic-directed self-assembly to prepare colloidal photonic crystal (CPC) supraparticles with controllable and predictable shape, and selectively introduced magnetic responsibility to them. The magnetic responsive Janus CPC supraparticles can be applied to biological analysis, optical instruments and chemical detection. $\mathrm{Xu}$ et al. [10] produced non-spherical microparticles with different shapes by producing colloidal aqueous suspension-gas Janus droplets in continuous oil phase. The method considerably improved both the optical performance and economy of photonic crystal microparticles fabrication.

As shown above, the solvent-extraction method prepares colloidal crystal microbeads with high efficiency and quality. However, the mechanisms of the method have not been thoroughly studied yet. On the other hand, anisotropic colloidal photonic crystal microparticles can be multifunctionalized and have great potential applications. Existing methods and devices to prepare them are all complicated and hard to control.

Inspiring approaches from Kuang [28,29], and Wu [30] et al. show controllable three-dimensional structures of printing droplets for high-resolution patterns with a focus on coffee-ring effect and Marangoni flow. They found that depinning the three phase contact line, restraining outward capillary flow and boosting inward Marangoni flow were helpful to suppress the coffee-ring effect.

In this work, we developed an advanced microfluidic approach to prepare anisotropic colloidal photonic crystal microparticles that is simple and easy to control. According to the study of colloidal photonic crystal self-assembly mechanisms and the "coffee ring" effect in strong extraction environment, we prepared anisotropic colloidal photonic crystal microparticles with great optical properties and special shapes by controlling the extraction rate and the size of droplets containing colloidal silica. 


\section{Extraction Strength's Effect on Macro-Structure of Photonic Crystal Particles}

We prepared colloidal silica nanoparticles with diameter of $220 \mathrm{~nm}$ by the Stöber method, and dispersed them into water with solid concentration of $3 \%$ to enter the dispersed phase. Dispersed phase fluid flow was sheared by continuous phase fluid (of same composition with extractant) to form monodispersed droplets in the microchannel. Then, the droplets flowed into a culture dish filled with extractant and stayed there until extraction finished. To change the extraction rate, we chose 1-octanol including $20 \mathrm{wt}$. \% octane, 1-octanol, 1-octanol including $20 \mathrm{wt}$ \% $\%$ n-Butanol, 1-octanol including $40 \mathrm{wt.} \% \mathrm{n}$-Butanol, 1-octanol including $60 \mathrm{wt}$. \% n-Butanol, 1-octanol including 80 wt. \% n-Butanol, and n-Butanol as extractant separately.

After the extraction, monodispersed droplets formed colloidal photonic crystal particles. According to Bragg's law, when the particle size $D=220 \mathrm{~nm}$, the reflective index $n_{\text {water }}=1.33$ and $n_{\text {sio } 2}=1.5$, and the surface of the spherical ball is assumed to be in the plane of the fcc packing symmetry, the calculated value was $524 \mathrm{~nm}$. We measured the optical effect of colloidal crystal particles by spectrograph, as shown in Figure 1. We obtained the reflectance peak at $530 \mathrm{~nm}$. It showed that the products were qualified for optical properties.

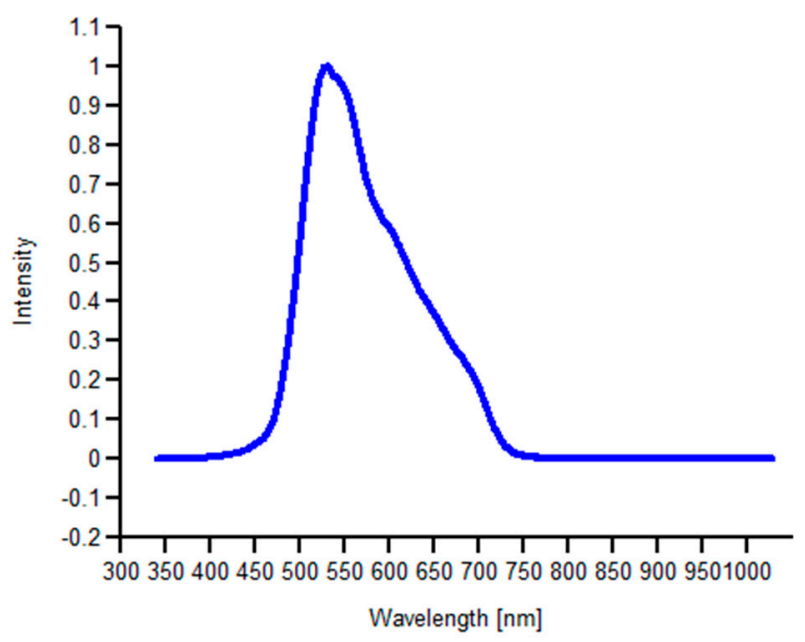

Figure 1. Reflectance spectrum of photonic crystal particles of colloidal silica nanoparticles.

Then we studied the extraction process of monodispersed droplets including colloidal silica nanoparticles, and found that it was influenced by the size of droplet and the composition of extractant. When the extractant was 1-octanol including $20 \mathrm{wt}$. \% octane, the extraction rate was slow and the time extraction needed was from $14 \mathrm{~min}$ to 1 hwith the size of droplet changing, as shown in Figure 2a. When that extractant was 1-octanol including $20 \mathrm{wt}$. \% n-Butanol, the extraction sped up significantly and the time the extraction needed was from 3 min to half an hour, as shown in Figure $2 \mathrm{~b}$. When that extractant was n-Butanol, the process of extraction was completed within $3 \mathrm{~min}$, as shown in Figure 2c. Moreover, the shape of particles was influenced greatly by extraction rate. They formed a toroidal even pie as the extraction sped up. With a certain extractant, the larger the droplet was, the longer the time extraction that was needed. Moreover, an increase of n-Butanol in extractant sped up extraction significantly. 

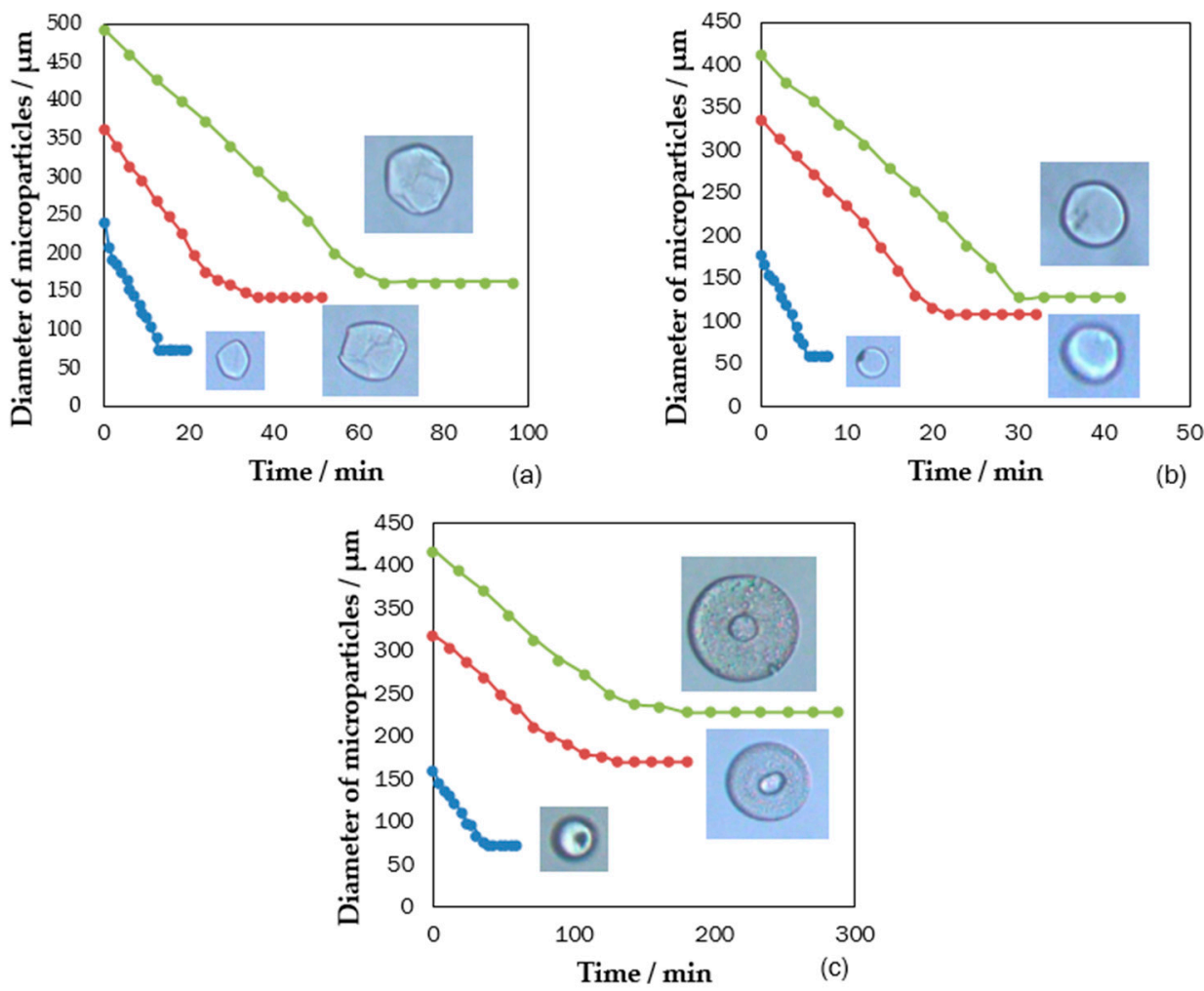

Figure 2. (a-c) The relationship between time extraction process required and droplets' diameter under the condition that extractant was 1-octanol including $20 \mathrm{wt}$. \% octane, 1-octanol including $20 \mathrm{wt}$ \% n-Butanol and n-Butanol separately.

\section{Results: Self-Assembly Kinetics of Colloidal Nanoparticle in Fabricating Anisotropic Colloidal Photonic Crystal Particles}

We put monodispersed droplets including colloidal silica into different extractants. In the end, they self-assembled to be photonic crystal particles with different shapes, such as spheres, stomatocytes, toroidals and pies, as shown in Figure 3. Among the photonic crystal particles, there were some cracked particles because we wanted to figure out their internal structures. The results showed that photonic crystal spheres were from solid to core-shell structure with the n-Butanol's percentage being larger. This is because the interface of extraction moved much faster than the diffusion of the nanoparticles in the droplets. The rapid shrinking of the droplet made the concentration of colloidal silica higher near the interface than in the center. Thus, the concentration of colloidal silica near the interface reached the critical concentration sooner than in the center of the droplet, causing the formation of a shell [24].

Then we systematically studied the effects of above conditions on the shape of colloidal photonic crystal particles and drew a graph to figure out the relationship between the shape of photonic crystal particles and the size of droplet and the composition of extractant, as shown in Figure 3q. We found that when the percentage of n-Butanol in extractant was less than $20 \%$, monodispersed droplets including colloidal silica self-assembled to be photonic crystal spheres. Moreover, when the percentage of n-Butanol in the extractant was more than $20 \%$ and less than $80 \%$, monodispersed droplets including colloidal silica self-organized to be photonic crystal stomatocytes more likely. When the percentage of n-Butanol in extractant was more than $80 \%$ and less than $100 \%$, monodispersed droplets including colloidal silica could self-assemble to be photonic crystal toroidals. In n-Butanol, monodispersed droplets including colloidal silica often self-assembled to be photonic crystal pies.

The reason why monodispersed droplets including colloidal silica self-assembled to be photonic crystal particles with different shapes is related to the "coffee ring" effect [31,32]. When a drop dries on a solid surface, its suspended particulate matter is deposited in ring-like fashion. Similar to this, 
when a droplet including colloidal silica flows into a culture dish filled with extractant, the colloidal silica nanoparticles deposit in a ring-like fashion in quick extraction environment. Because colloidal silica is a sphere and easy to roll, there is an internal circumfluence inside the microdroplet in a quick extraction environment, which results in colloidal silica being more likely to deposit at the margin of the droplet.
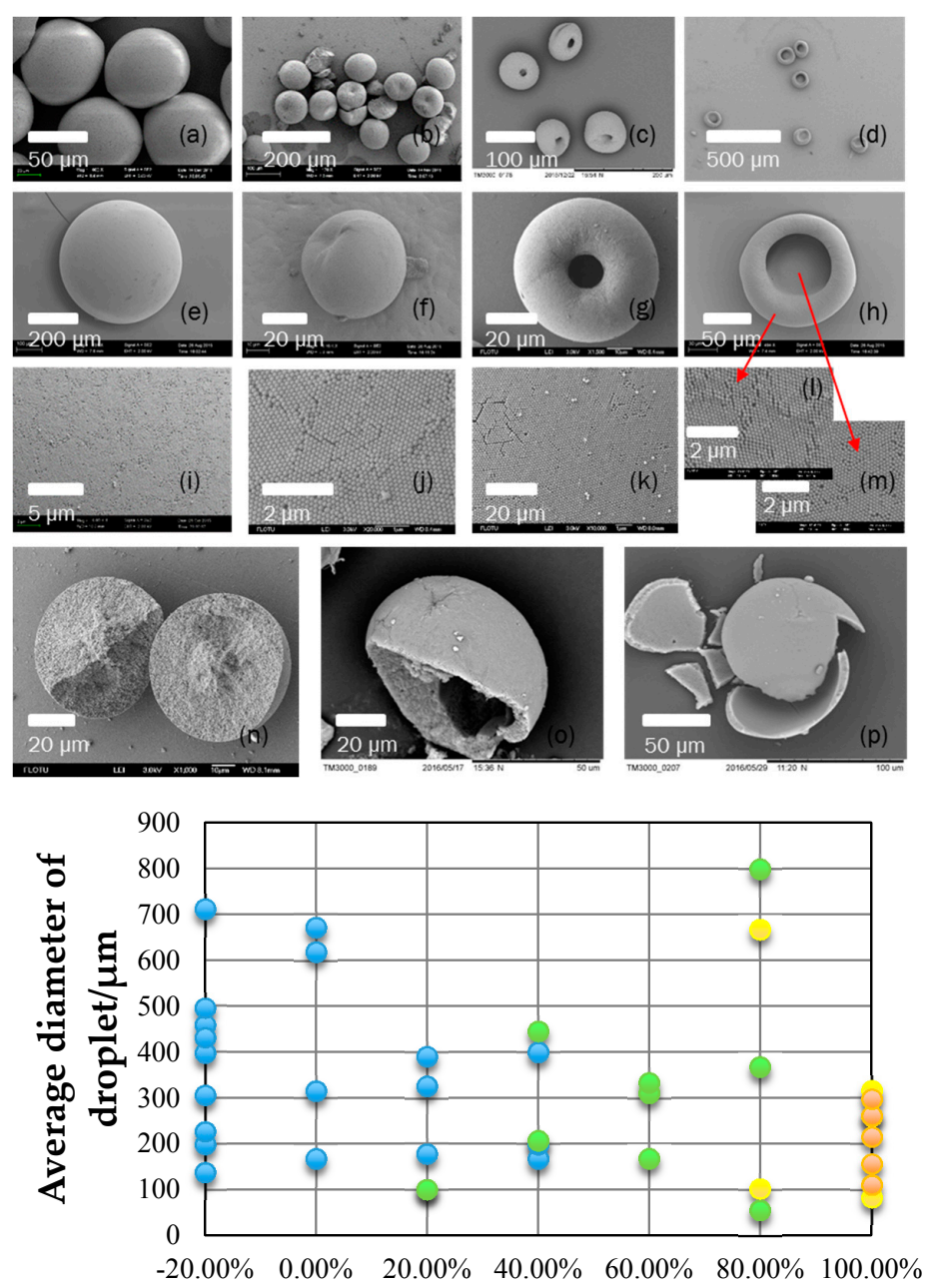

(q)

Figure 3. (a-d) SEM images of many photonic crystal particles with the same shape. (e-h) SEM images of photonic crystal particles with different shapes, including spheres, stomatocytes, toroidals and pies. (i-m) Partial surface of photonic crystal particles (e-h) respectively. (n-p) The internal structures of photonic crystal particles. Photonic crystal spheres (a,e) were extracted by 1-octanol including 20 wt. \% octane, photonic crystal particles like stomatocytes $(\mathbf{b}, \mathbf{f})$ were extracted by 1-octanol including 20 wt. \% n-Butanol, photonic crystal toroidals (c,g) were extracted by 1-octanol including 80 wt. \% n-Butanol, photonic crystal particles like pies $(\mathbf{d}, \mathbf{h})$ were extracted by n-Butanol. (q) The relationship between the shape of photonic crystal particles and the size of droplet, the composition of extractant. Blue dots represent that shapes of particles are spheres; green dots represent stomatocytes; yellow dots represent toroidals; orange dots represent pies. Horizontal axis means the percentage of n-Butanol in extractant, and $-20.00 \%$ means extractant is 1 -octanol including $20 \mathrm{wt}$. \% octane, $0.00 \%$ means extractant is 1-octanol.

When the extraction rate was slow, the droplet including colloidal silica shrunk slowly and formed a perfect sphere. When the n-Butanol in extractant was more than $20 \%$, faster extraction rate made photonic crystal form toroidals and pies instead of spheres. The formation process of photonic crystal 
toroidal was shown in Figure 4a, and the video showing the process was in the Supporting Information (Movie S1). The three phase contact line moved much faster than the diffusion of the nanoparticles in the droplets because of the fast extraction rate. The concentration of colloidal silica near the three phase contact line was higher than in the center. Thus, the circumferential region of the droplet solidified first. Radial swirling flows in the droplet moved colloidal silica towards the solidified surface continuously, as shown in schematic Figure $4 b$ [33]. The original spherical droplet was stretched and pinched until the center broke to form a hole [34]. Finally the droplet was extracted to form a photonic crystal toroidal. However, when the n-Butanol in extractant was $80 \%$, the extraction rate was so fast that time for the radial swirling flows was not enough to move all colloidal silica. So, the remaining colloidal silica tiled on the substrate and made photonic crystal particles like a pie.

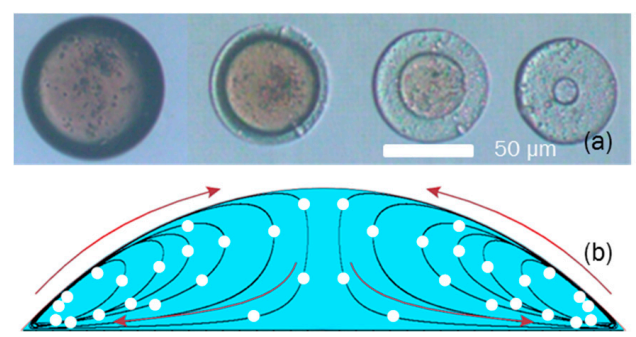

Figure 4. (a) The formation process of photonic crystal toroidal. (b) The schematic of droplet extraction before forming toroidal.

\section{Results: Optical Characterization}

From the optical images and reflectance spectrum in Figure 5 we found that photonic crystal particles with different shapes reflected green light well, and the reflectance peaks were around $530 \mathrm{~nm}$ following Bragg's Law well. The photonic crystal particles like toroidals and pies showed better optical property than photonic crystal spheres. In the quick extraction process, the partial concentration of colloidal particles at the margin of the droplet was higher compared with other parts of the droplet, which resulted in the packing quality at the margin of the photonic crystal particle being better. Then, the integral optical properties were improved. As shown in Figure 3i-m, the packing quality of the photonic crystal toroidals and pies surface were better than the photonic crystal spheres. However, the margin of the photonic crystal pies did not pack well so their reflectance peak was not as sharp as photonic crystal toroidals'.

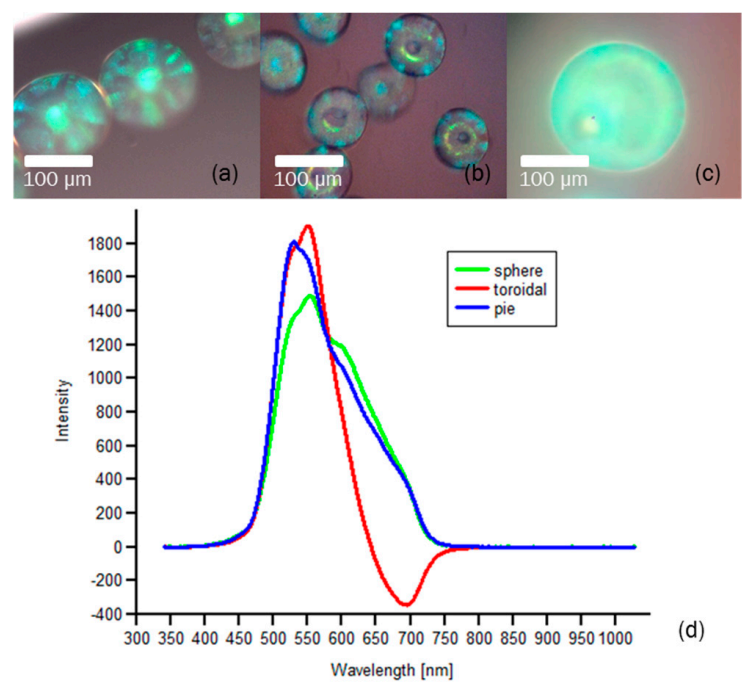

Figure 5. (a-c) Optical images and (d) reflectance spectrum of photonic crystal particles with different shapes. 


\section{Polystyrene Photonic Crystal Particles}

Besides colloidal silica photonic crystal particles, we could also produce polystyrene photonic crystal particles. When the extractant was 1-octanol including $20 \mathrm{wt}$. \% octane, monodispersed droplets including colloidal polystyrene self-organized to be photonic crystal stomatocytes, as shown in Figure 6a,c. And when extractant was 1-octanol including $40 \mathrm{wt}$. \% n-Butanol, monodispersed droplets including colloidal polystyrene self-assembled to be photonic crystal particles like bowls, as shown in Figure $6 \mathrm{~b}, \mathrm{~d}$. The photonic crystal particles reflected pink light well, and the reflectance peaks were around $610 \mathrm{~nm}$ following Bragg's Law (the result of theoretic calculation was $620 \mathrm{~nm}$ ) well, as shown in Figure 6e.

In this work, we prepared anisotropic photonic crystal microparticles of colloidal silica and polystyrene nanoparticles respectively. Both kinds of photonic crystal microparticles reflected light and followed Bragg's law well. Surface of silica spherical particles is easier to physically and chemically modified. While polystyrene nanoparticles melt more easily and dissolve in organic solvent. So photonic crystal microparticles of colloidal silica may have more potential applications than photonic crystal microparticles of polystyrene nanoparticles.
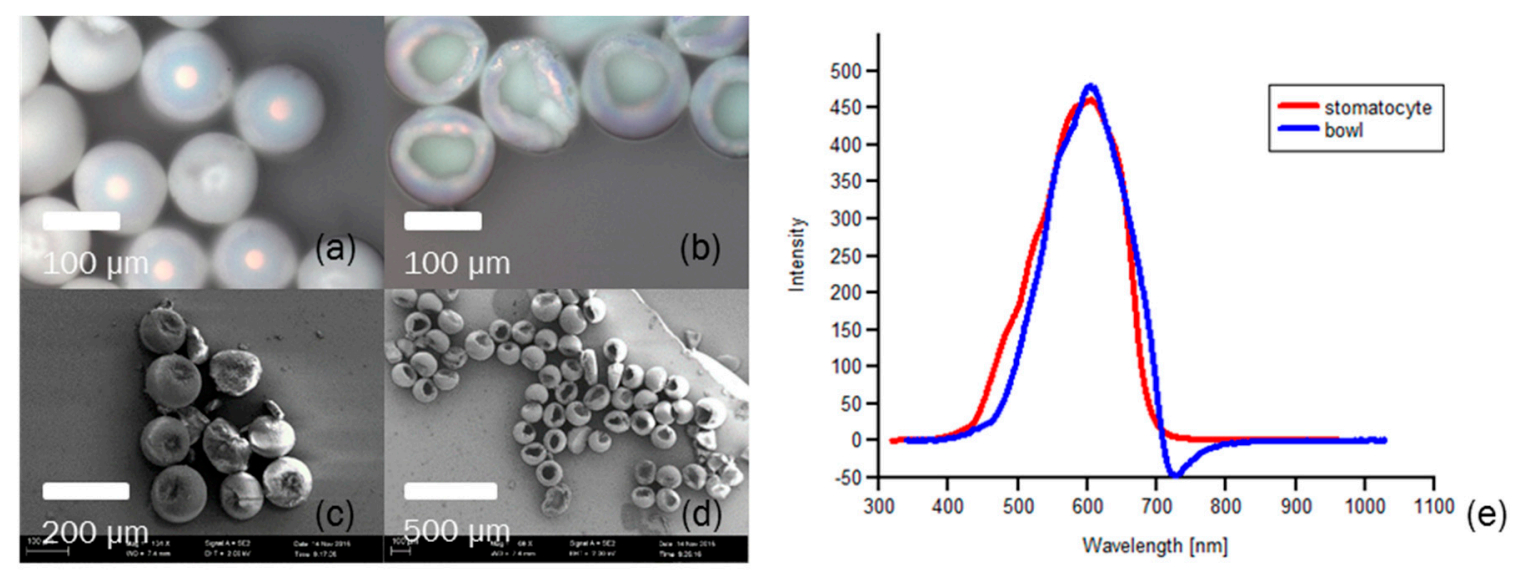

Figure 6. Optical images (a,b), SEM images (c,d) and reflectance spectrum (e) of polystyrene photonic crystal particles with different shapes.

\section{Experimental Details}

\subsection{Chemicals, Materials and Characterization}

The microfluidic device was fabricated on a polymethyl methacrylate (PMMA) plate by using a Computerized Numerical Control (CNC) machine tool with end mills $(\Phi=0.2 \mathrm{~mm}$ and $\Phi=0.3 \mathrm{~mm})$, as shown in Figure 7a. The width and the depth of microchannel of dispersed phase are both $0.2 \mathrm{~mm}$, and these of continuous phase are both $0.3 \mathrm{~mm}$. Dispersed phase fluid flow (green fluid in the figure) was driven into the microchannel, then sheared by continuous phase fluid (yellow fluid) to form monodispersed droplets. Then, the droplets flowed into a culture dish filled with extractant. We controlled the size of monodispersed droplets by changing the flow rate of the continuous phase.

To prepare the dispersed phase, we prepared colloidal silica with diameter of $220 \mathrm{~nm}$ by the Stöber method that was first described in 1968 [35], and dispersed colloidal silica into water with solid concentration of $3 \%$ as the dispersed phase. 1-octanol and n-Butanol extract water fast and will not hurt optical property of photonic crystal. To change extraction rate, we chose 1-octanol including $20 \mathrm{wt}$ \% octane, 1-octanol, 1-octanol including 20 wt. \% n-Butanol, 1-octanol including 40 wt. \% n-Butanol, 1-octanol including 60 wt. \% n-Butanol, 1-octanol including $80 \mathrm{wt}$ \% $\%$-Butanol, and n-Butanol as extractant separately. The continuous phase was the same as the extractant. 

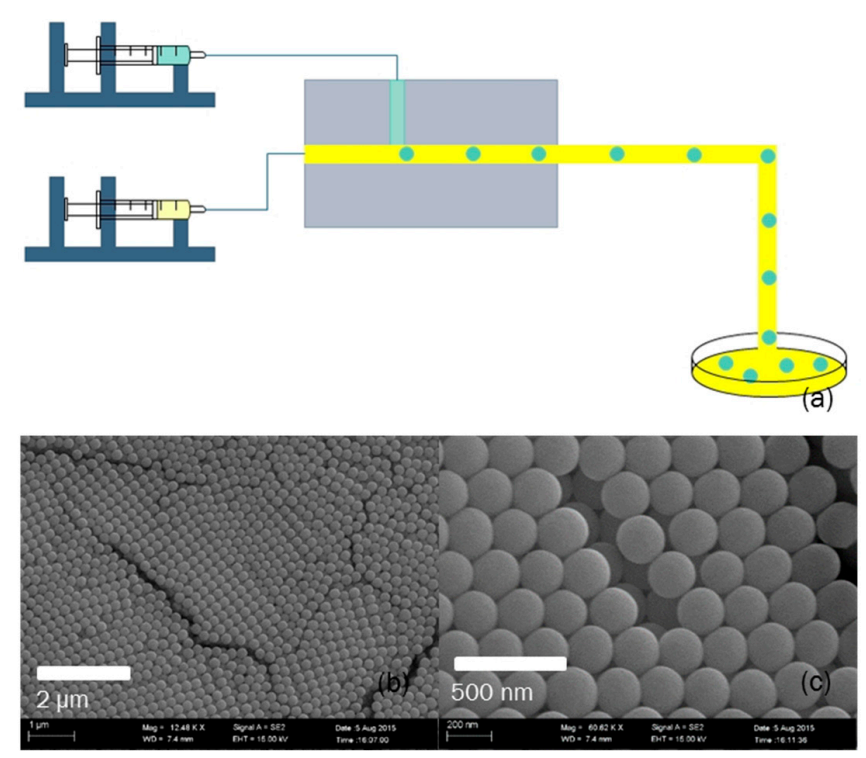

Figure 7. (a) The structure of the microfluidic device. (b,c) The SEM images of monodispersed colloidal silica nanoparticles.

We observed the formation and extraction processes of colloidal crystal droplets by an optical microscope (Olympus, Tokyo, Japan) equipped with a camera (B742U, Pixelink, Ottawa, ON, Canada). The optical effect of colloidal crystal particles was measured by spectrograph and the shape was observed under SEM (MERLIN Compact, ZEISS, Oberkochen, Germany) (All the experiments were carried out at room temperature).

\subsection{Colloidal Photonic Crystal Droplets Preparation}

We prepared monodispersed colloidal silica with uniform size and good sphericity by the Stöber method. With ammonia as the catalyst, tetraethyl orthosilicate hydrolyzed in ethanol and created monodispersed colloidal silica spherical particles. The Stöber method could select to produce highly monodispersed silica spherical particles within a certain diameter range by changing reaction condition. Besides, surface of silica spherical particles produced by this method is easy to physically and chemically modified, which resulted that we could functionalize the particles and enlarge their application area.

In experiments, we produced highly monodispersed silica spherical particles with diameter from $140 \mathrm{~nm}$ to $220 \mathrm{~nm}$ by adding more ammonia. According to Bragg's Law, we knew that the reflected electromagnetic wave of colloidal photonic crystal closely packed by silica spherical particles with diameter of $220 \mathrm{~nm}$ was green light. So we chose colloidal silica spherical particles with diameter of $220 \mathrm{~nm}$ to do our experiments, as shown in Figure $7 \mathrm{~b}, \mathrm{c}$.

\section{Conclusions}

In this work, we developed a new approach to preparing anisotropic colloidal photonic crystal microparticles. The approach is simple and controllable. According to the study of colloidal photonic crystal self-assembly kinetics and the "coffee ring effect" in strong extraction environment, we produced anisotropic colloidal photonic crystal microparticles with different unique shapes, via adjusting the extraction rate and the size of droplets containing colloidal silica. The fabricated particles showed good optical properties. In addition, we also produced polystyrene photonic crystal particles, which showed similar mechanisms with colloidal silica photonic crystal particles. The result provides important theoretical contributions and has potential applications in a variety of fields including optical communication technology, environmental response, photo-catalysis and chromic material. 
Supplementary Materials: The following are available online at http:/ /www.mdpi.com/2073-4352/6/10/122/s1. Movie S1: The extraction process of droplet.

Acknowledgments: The authors gratefully acknowledge the supports of the National Natural Science Foundation of China $(21322604,21136006,21476121)$.

Author Contributions: Ming-Yu Zhang designed and performed the experiments, and wrote the paper. Ke Xu, Jian-Hong $\mathrm{Xu}$ and Guang-Sheng Luo revised the paper.

Conflicts of Interest: The authors declare no conflict of interest. The founding sponsors had no role in the design of the study; in the collection, analyses, or interpretation of data; in the writing of the manuscript, and in the decision to publish the results.

\section{References}

1. Yablonovitch, E. Inhibited spontaneous emission in solid-state physics and electronics. Phys. Rev. Lett. 1987, 58, 2059-2062. [CrossRef] [PubMed]

2. John, S. Strong localization of photons in certain disordered dielectric superlattices. Phys. Rev. Lett. 1987, 58, 2486-2489. [CrossRef] [PubMed]

3. Lopez, C. Materials aspects of photonic crystals. Adv. Mater. 2003, 15, 1679-1704. [CrossRef]

4. Wijnhoven, J.; Vos, W.L. Preparation of photonic crystals made of air spheres in titania. Science 1998, 281, 802-804. [CrossRef]

5. Vlasov, Y.A.; Bo, X.Z.; Sturm, J.C.; Norris, D.J. On-chip natural assembly of silicon photonic bandgap crystals. Nature 2001, 414, 289-293. [CrossRef] [PubMed]

6. Kim, S.H.; Lee, S.Y.; Yi, G.R.; Pine, D.J.; Yang, S.M. Microwave-assisted self-organization of colloidal particles in confining aqueous droplets. J. Am. Chem. Soc. 2006, 128, 10897-10904. [CrossRef] [PubMed]

7. Zhang, J.; Sun, Z.; Yang, B. Self-assembly of photonic crystals from polymer colloids. Curr. Opin. Colloid Interface Sci. 2009, 14, 103-114. [CrossRef]

8. Xu, J.H.; Ge, X.H.; Chen, R.; Luo, G.S. Microfluidic preparation and structure evolution of double emulsions with two-phase cores. RSC Adv. 2014, 4, 1900-1906. [CrossRef]

9. Nie, Z.H.; Xu, S.Q.; Seo, M.; Lewis, P.C.; Kumacheva, E. Polymer particles with various shapes and morphologies produced in continuous microfluidic reactors. J. Am. Chem. Soc. 2005, 127, 8058-8063. [CrossRef] [PubMed]

10. Xu, K.; Xu, J.-H.; Lu, Y.-C.; Luo, G.-S. A novel method of fabricating, adjusting, and optimizing polystyrene colloidal crystal nonspherical microparticles from gas-water janus droplets in a double coaxial microfluidic device. Cryst. Growth Des. 2014, 14, 401-405. [CrossRef]

11. Nisisako, T.; Torii, T. Formation of biphasic janus droplets in a microfabricated channel for the synthesis of shape-controlled polymer microparticles. Adv. Mater. 2007, 19, 1489-1493. [CrossRef]

12. Lan, W.; Li, S.; Xu, J.; Luo, G. A one-step microfluidic approach for controllable preparation of nanoparticle-coated patchy microparticles. Microfluid Nanofluid 2012, 13, 491-498. [CrossRef]

13. Prasad, N.; Perumal, J.; Choi, C.-H.; Lee, C.-S.; Kim, D.-P. Generation of monodisperse inorganic-organic janus microspheres in a microfluidic device. Adv. Funct. Mater. 2009, 19, 1656-1662. [CrossRef]

14. Ono, T.; Yamada, M.; Suzuki, Y.; Taniguchi, T.; Seki, M. One-step synthesis of spherical/nonspherical polymeric microparticles using non-equilibrium microfluidic droplets. RSC Adv. 2014, 4, 13557-13564. [CrossRef]

15. Asher, S.A.; Holtz, J.; Liu, L.; Wu, Z.J. Self-assembly motif for creating submicron periodic materials. Polymerized crystalline colloidal arrays. J. Am. Chem. Soc. 1994, 116, 4997-4998. [CrossRef]

16. Rundquist, P.A.; Photinos, P.; Jagannathan, S.; Asher, S.A. Dynamical bragg-diffraction from crystalline colloidal arrays. J. Chem. Phys. 1989, 91, 4932-4941. [CrossRef]

17. Jiang, P.; Bertone, J.F.; Hwang, K.S.; Colvin, V.L. Single-crystal colloidal multilayers of controlled thickness. Chem. Mater. 1999, 11, 2132-2140. [CrossRef]

18. Mihi, A.; Ocana, M.; Miguez, H. Oriented colloidal-crystal thin films by spin-coating microspheres dispersed in volatile media. Adv. Mater. 2006, 18, 2244-2249. [CrossRef]

19. Jiang, P.; McFarland, M.J. Large-scale fabrication of wafer-size colloidal crystals, macroporous polymers and nanocomposites by spin-coating. J. Am. Chem. Soc. 2004, 126, 13778-13786. [CrossRef] [PubMed] 
20. Wong, S.; Kitaev, V.; Ozin, G.A. Colloidal crystal films: Advances in universality and perfection. J. Am. Chem. Soc. 2003, 125, 15589-15598. [CrossRef] [PubMed]

21. Sun, C.; Zhao, X.W.; Zhao, Y.J.; Zhu, R.; Gu, Z.Z. Fabrication of colloidal crystal beads by a drop-breaking technique and their application as bioassays. Small 2008, 4, 592-596. [CrossRef] [PubMed]

22. Kim, S.-H.; Jeon, S.-J.; Yi, G.-R.; Heo, C.-J.; Choi, J.H.; Yang, S.-M. Optofluidic assembly of colloidal photonic crystals with controlled sizes, shapes, and structures. Adv. Mater. 2008, 20, 1649-1655. [CrossRef]

23. Zhao, X.; Cao, Y.; Ito, F.; Chen, H.-H.; Nagai, K.; Zhao, Y.-H.; Gu, Z.-Z. Colloidal crystal beads as supports for biomolecular screening. Angew. Chem. Int. Ed. 2006, 45, 6835-6838. [CrossRef] [PubMed]

24. Xu, K.; Xu, J.H.; Lu, Y.C.; Luo, G.S. Extraction-derived self-organization of colloidal photonic crystal particles within confining aqueous droplets. Cryst. Growth Des. 2013, 13, 926-935. [CrossRef]

25. Yu, Z.; Wang, C.-F.; Ling, L.; Chen, L.; Chen, S. Triphase microfluidic-directed self-assembly: Anisotropic colloidal photonic crystal supraparticles and multicolor patterns made easy. Angew. Chem. Int. Ed. 2012, 51, 2375-2378. [CrossRef] [PubMed]

26. Kim, S.-H.; Jeon, S.-J.; Jeong, W.C.; Park, H.S.; Yang, S.-M. Optofluidic synthesis of electroresponsive photonic janus balls with isotropic structural colors. Adv. Mater. 2008, 20, 4129-4134. [CrossRef]

27. Kim, S.H.; Lim, J.M.; Jeong, W.C.; Choi, D.G.; Yang, S.M. Patterned colloidal photonic domes and balls derived from viscous photocurable suspensions. Adv. Mater. 2008, 20, 3211-3217. [CrossRef]

28. Kuang, M.X.; Wang, L.B.; Song, Y.L. Controllable printing droplets for high-resolution patterns. Adv. Mater. 2014, 26, 6950-6958. [CrossRef] [PubMed]

29. Kuang, M.; Wu, L.; Li, Y.; Gao, M.; Zhang, X.; Jiang, L.; Song, Y. Sliding three-phase contact line of printed droplets for single-crystal arrays. Nanotechnology 2016, 27, 184002. [CrossRef] [PubMed]

30. Wu, L.; Dong, Z.C.; Kuang, M.X.; Li, Y.N.; Li, F.Y.; Jiang, L.; Song, Y.L. Printing patterned fine 3D structures by manipulating the three phase contact line. Adv. Funct. Mater. 2015, 25, 2237-2242. [CrossRef]

31. Deegan, R.D.; Bakajin, O.; Dupont, T.F.; Huber, G.; Nagel, S.R.; Witten, T.A. Capillary flow as the cause of ring stains from dried liquid drops. Nature 1997, 389, 827-829. [CrossRef]

32. Yunker, P.J.; Still, T.; Lohr, M.A.; Yodh, A.G. Suppression of the coffee-ring effect by shape-dependent capillary interactions. Nature 2011, 476, 308-311. [CrossRef] [PubMed]

33. Sempels, W.; De Dier, R.; Mizuno, H.; Hofkens, J.; Vermant, J. Auto-production of biosurfactants reverses the coffee ring effect in a bacterial system. Nat. Commun. 2013, 4. [CrossRef] [PubMed]

34. Wang, B.G.; Shum, H.C.; Weitz, D.A. Fabrication of monodisperse toroidal particles by polymer solidification in microfluidics. ChemPhysChem 2009, 10, 641-645. [CrossRef] [PubMed]

35. Stober, W.; Fink, A.; Bohn, E. Controlled growth of monodisperse silica spheres in micron size range. J. Colloid Interface Sci. 1968, 26, 62-69. [CrossRef]

(C) 2016 by the authors; licensee MDPI, Basel, Switzerland. This article is an open access article distributed under the terms and conditions of the Creative Commons Attribution (CC-BY) license (http:/ / creativecommons.org/licenses/by/4.0/). 